무전해 니켈 · 팔라듐 · 금도금 표면처리 공정의 도금 번짐 불량 및 개선

\author{
엄기헌, 서정욱 ${ }^{\dagger}$, 원용선* \\ 부경대학교 화학공학과 \\ 608-739 부산광역시 남구 용당동 산 100 \\ ${ }^{\dagger}$ 삼성전기주식회사 생산기술센터 \\ 443-743 경기도 수원시 영통구 매탄 3 동 314
}

(2013년 3월 15일 접수; 2013년 3월 28일 수정본 접수; 2013년 3월 28일 채택)

\title{
Prevention of Running Blots between the Patterns during the Electroless Nickel Electroless Palladium Immersion Gold (ENEPIG) Surface Finish
}

\author{
$\mathrm{Ki}$ Heon Eom, Jung-wook $\mathrm{Seo}^{\dagger}$, and Yong Sun Won* \\ Department of Chemical Engineering, Pukyong National University \\ San 100 Yongdang-dong, Nam-gu, Busan 608-739, Korea \\ ${ }^{\dagger}$ Manufacturing \& Engineering Center, Samsung Electro-Mechanics Co., Ltd. \\ 314 Maetan 3-dong, Yeongtong-gu, Suwon-si, Gyunggi 443-743, Korea
}

(Received for review March 15, 2013; Revision received March 28, 2013; Accepted March 28, 2013)

\section{요 약}

무전해 니켈 - 팔라듐 · 금 표면처리 공정의 도금 번짐 불량의 근본적인 원인을 이해하고 이를 해결하기 위한 방법을 제시하 였다. 이에 계산화학을 이용하여 공정을 정성적으로 설명하고 이를 바탕으로 가정을 검증하기 위한 실험을 계획하였다. 도 금 번짐으로 발전되는 고분자 레진 위의 팔라듐 시드의 핵 생성을 막는 것에 초점을 맞추어 고분자 레진과 화학적으로 결합 력이 약한 $\mathrm{PdCl}_{2}$ 팔라듐 촉매를 도입하였으며 이 촉매가 수용액 중에서 추가적인 가수분해 반응으로 더 안정한 $\mathrm{Pd}(\mathrm{OH})_{2}$ 를 형성함으로써 고분자 레진 위에 팔라듐 시드의 원천으로 작용하지 않도록 염산 $(\mathrm{HCl})$ 의 농도를 높이거나 팔라듐 활성화 공 정의 온도를 낮추어 보았다. 계산화학은 매 단계 실험의 이론적인 근거를 제시해 주었으며 실험 결과를 해석하는 데 큰 도움 을 주었다. 이와 같이 실험과 이론을 접목시킨 본 연구의 접근법은 관련 공정에서 매우 유용하게 활용될 수 있을 것으로 기 대된다.

주제어 : 무전해 니켈·팔라듐·금 도금, 인쇄회로기판, 팔라듐 활성화제, 계산화학, 범밀도함수이론

\begin{abstract}
The running blots between patterns during electroless nickel electroless palladium immersion gold (ENEPIG) surface finish of printed circuit board (PCB) are investigated and a proper solution is presented. Computational chemistry is first employed to understand the process and experiments are then designed to verify the proposed ideas. $\mathrm{A} \mathrm{PdCl}_{2}$ activator which has relatively weak chemical bonding to the epoxy resin is introduced to prevent the formation of palladium seeds on the epoxy resin and a couple of operational measures such as increasing $\mathrm{HCl}$ concentration and lowering the temperature of $\mathrm{Pd}$ activation process are executed to prevent a further hydrolysis of $\mathrm{PdCl}_{2}$ to more stable $\mathrm{Pd}(\mathrm{OH})_{2}$ in aqueous solution. Computational chemistry provides thermodynamic backgrounds for experiments and their results. This combined approach is expected to be very useful in the research of relevant processes.
\end{abstract}

Keywords : Electroless nickel electroless palladium immersion gold (ENEPIG), Printed circuit board (PCB), Pd activator, Computational chemistry, Density functional theory

\footnotetext{
* To whom correspondence should be addressed. E-mail: yswon@pknu.ac.kr
} doi:10.7464/ksct.2013.19.2.084

\section{1. 서 론}

지금까지 고신뢰성 인쇄회로기판(printed circuit board, PCB) 의 표면처리를 위해 무전해 니켈 · 금(electroless nickel immersion gold, ENIG) 표면처리공법이 광범위하게 사용되어 왔다. 
하지만 최근 들어 이미 10 여 년 전에 기존 $\mathrm{ENIG}$ 의 주요 불량 원인인 과부식(hyper-corrosion) 혹은 블랙패드(black pad) 문 제를 해결하기 위해 제시된 기술이었으나 상대적으로 복잡한 공정으로 인해 비용적인 이점이 크지 않아 적용되지 않았던 무전해 니켈 - 팔라듐 · 금(electroless nickel electoless palladium immersion gold, ENEPIG) 공법이 ENIG를 대체하는 추세이다 [1-4]. 그 이유는 급격히 상승한 금 가격 때문인데[5] Figure 1(a) 와 (b)에서 보는 바와 같이 ENEPIG의 경우 최종 금 도금의 두

(a)

\begin{tabular}{|c|r}
\hline $\mathrm{Au}$ & $0.7 \mu \mathrm{m}$ \\
$\mathrm{Ni}-\mathrm{P}(6-8 \%)$ & $3-8 \mu \mathrm{m}$ \\
$\mathrm{Cu}$ & \\
Base & \\
\end{tabular}

(b)

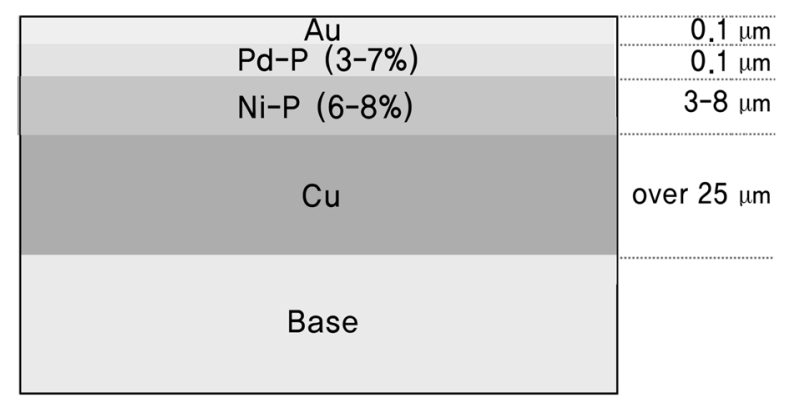

(c)

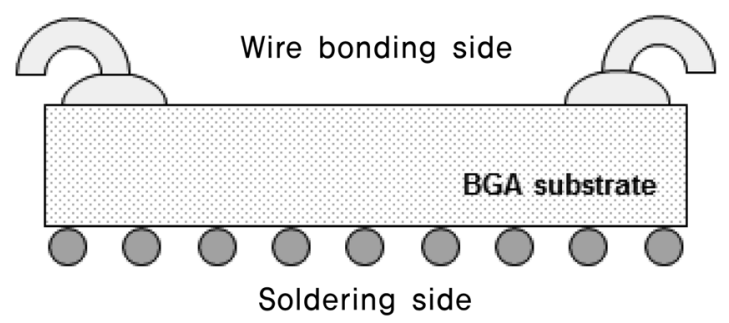

Figure 1. Cross-sectional composition of ENIG (a) and ENEPIG (b) surface finish, and the schematic of the overall PCB structure (c).
께가 $0.1 \mu \mathrm{m}$ 로 $\mathrm{ENIG}$ 의 $0.7 \mu \mathrm{m}$ 에 비해 매우 얇아 또 다른 귀 금속인 팔라듐의 추가 도금으로 인한 비용 발생을 보상하고도 전체적으로 약 $30 \%$ 이상의 원가를 절감할 수 있는 것으로 알 려진다. 또한 앞서 언급했듯이 $0.1 \mu \mathrm{m} \mathrm{Pd-P(P의} \mathrm{함량} \mathrm{3} \mathrm{7 \% )}$ 층의 존재로 기존 $\mathrm{ENIG}$ 의 $\mathrm{IG}$ 공정에서 발생하는 니켈 층의 과부식을 방지하여 블랙패드 불량[6]을 해결할 수 있다. 그리 고 Figure 1(c)에서 보듯이 표면 처리 후에 와이어본딩(wire bonding)과 BGA 솔더링(ball grid array soldering) 공정이 있는 데 와이어본딩 시 Pd-P층이 니켈의 금 층으로의 확산을 방지 하여 와이어본딩 신뢰성(bondability)을 좋게 해주며 솔더링 시 에는 얇아진 금 층이 $\mathrm{ENIG}$ 의 경우처럼 두꺼운 금 층의 금 성 분과 솔더볼(solder ball)의 주석 성분이 금 - 주석 합금을 형성 함으로써 발생하는 솔더링 신뢰성(solderability)의 저하를 막 아준다[1,4]. 참고로 도금층 내의 인 $(\mathrm{P})$ 의 존재는 무전해 니켈 과 무전해 팔라듐 공정에서 금속이온의 환원제로 $\mathrm{NaPO}_{2} \mathrm{H}_{2}$. $\mathrm{H}_{2} \mathrm{O}$ (hydrated sodium hypophosphite)가 사용되고 반응 중에 도금층 내부에 일부 침적되기 때문이다.

그런데 기판의 경박단소화로 피치(pitch)가 줄어듦에 따라 Figure 2와 같이 도금 번짐에 의한 쇼트가 발생하는 문제가 발생하였다. 피치가 $105 \mu \mathrm{m}$ 이하인 기판에서 문제가 발생하 였는데 Figure 3(a)의 추가 분석 결과와 같이 비록 도금 번짐 이 패턴의 측면이 심하지만 패턴의 측면에서 성장하는 것이 아니라 고분자 레진 위에서 형성되는 것으로 판단되며 니켈 층을 올리기 위해 구리 위에 팔라듐 시드(seed)를 먼저 깔아주 는 팔라듐 활성화(Pd activation) 공정 후 고분자 레진 표면을 관찰한 결과(Figure 3(b)) 고분자 레진 위에도 팔라듐 시드들 이 형성된 것을 확인할 수 있었다. 따라서 이러한 팔라듐 시드 들을 핵으로 하여 ENEPIG 공정을 차례로 거치면서 도금 번짐 이 발생한 것으로 판단된다. 한편 고분자 레진 위에는 복잡한 다층 방청금속 층 $(\mathrm{Ni}, \mathrm{Cr}, \mathrm{Zn}, \mathrm{Mo}, \mathrm{Co}$ 등)이 존재하는데 방청 금속 층이 없는 고가의 재료를 사용하면 위와 같은 도금 번짐 현상이 발생하지 않는 것으로 보아 고분자 레진 위의 잔존 방 청금속들도 팔라듐 활성화 공정에서 팔라듐 시드의 형성에 영 향을 주는 것으로 보인다.

그러나 원가 상승이 발생하기 때문에 방청금속 층이 없는 고가의 기판 재료를 사용하는 것은 바람직하지 않으며 테스트
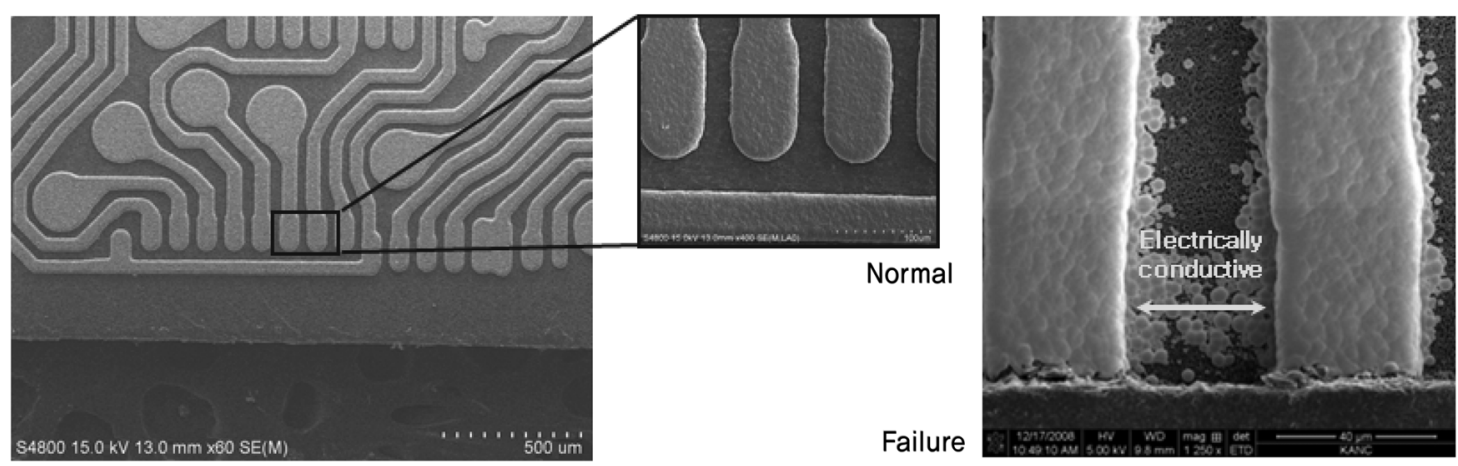

Figure 2. Short failure due to the running blots between patterns. 

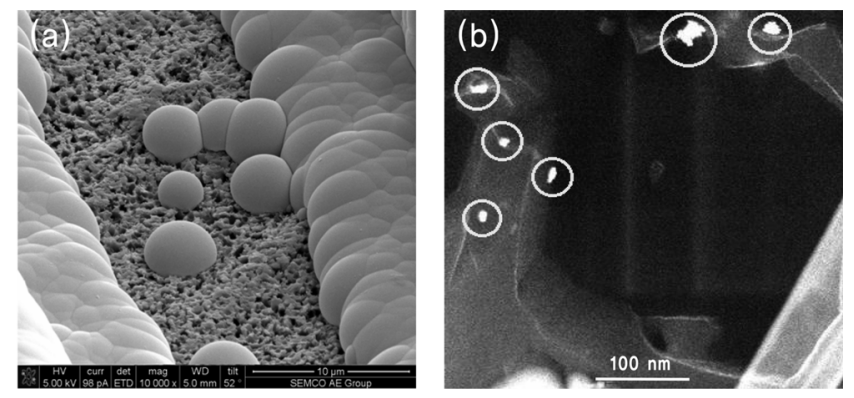

Figure 3. SEM morphology of the running blots (a) and the palladium seeds (b) on the epoxy resin observed by TEM.

결과 방청금속을 $100 \%$ 제거하는 것 또한 쉽지 않고 이를 위한 식각(etch) 공정시간을 늘이게 되면 전체 공정의 공정시간(lead time)도 늘어나 생산성 저하가 발생한다. 이에 이번 연구에서 는 앞서 언급한 고분자 레진 위의 팔라듐 시드(seed)의 생성을 최소화하는 데에 초점을 맞추어 ENEPIG 공정의 도금 불량을 해결하는 방법을 제시하고자 한다. 이에 대한 물리화학적인 이 해를 위해 계산화학을 도입하였으며 계산화학 결과를 바탕으 로 실험을 계획하고 가정을 검증하였다.

\section{2. 실 험}

\subsection{ENEPIG 공정}

ENEPIG 공정도를 Figure 4에 간단하게 정리하였다. 실험은 무전해 니켈(electroless Ni-P) 단계까지만 진행하여 패널(panel) 의 $1 / 4$ 크기인 시편의 도금 번짐을 관찰하였다. Table 1 에 간 단한 실험 조건을 정리하였으며 BGA ENEPIG 우에무라(Uyemura) 공정 표준 조건에 따른다. 이에 대한 자세한 설명은 참고 문헌[6]에서 찾을 수 있다.

\section{2. 기기분석}

투과전자현미경(transmission electron microscopy, TEM)
Table 1. Basic experimental conditions

\begin{tabular}{|c|c|c|c|c|c|c|c|c|}
\hline & \multicolumn{2}{|c|}{ Chemicals } & \multicolumn{2}{|c|}{ Temp. $\left({ }^{\circ} \mathrm{C}\right)$} & $\mathrm{pH}$ & \multicolumn{3}{|c|}{ Time (min) } \\
\hline Cleaner & \multicolumn{2}{|c|}{ ACL-007 } & \multicolumn{2}{|c|}{50} & - & \multicolumn{3}{|c|}{5} \\
\hline Soft etch & \multicolumn{2}{|c|}{$\begin{array}{c}\text { Oxon }+ \\
\text { Sulfuric acid }\end{array}$} & \multicolumn{2}{|c|}{28} & - & $\begin{array}{l}40 \\
\sec \end{array}$ & & 2 \\
\hline Pre-dip & \multicolumn{2}{|c|}{ Sulfuric acid $10 \%$} & \multicolumn{2}{|c|}{ Room temp. } & - & \multicolumn{3}{|c|}{1} \\
\hline $\begin{array}{c}\mathrm{Pd} \\
\text { activation }\end{array}$ & $\mathrm{MNK}$ & MSR-41 & 20 & 30 & - & $\begin{array}{l}40 \\
\text { sec }\end{array}$ & & 2 \\
\hline $\begin{array}{c}\text { Electroless } \\
\text { Ni-P }\end{array}$ & \multicolumn{2}{|c|}{ NPR-4 } & 77 & 80 & 4.6 & 30 & & 23 \\
\hline
\end{tabular}

이미지는 JEOL JEM $1200 \mathrm{EX} \mathrm{II}(80 \mathrm{kV})$ 를 사용하여 얻어졌으 며 주사전자현미경(scanning tunneling microscopy, SEM) 이미 지는 FEI Nova NanoSEM $200(10 \mathrm{kV})$ 를 사용하여 얻어졌다. 광학현미경으로 Nikon ECLIPSE 1200을 사용하여 도금 번짐 정도를 관찰하였다.

\section{3. 계산화학}

반응 에너지 계산을 위하여 밀도범함수이론(density functional method, DFT)[7] 중 가장 일반적으로 사용되는 3인자 범함수(functional)인 B3LYP model chemistry를 사용하였으며 밀도함수를 구하기 위해 쓰이는 기저집합(basis set)으로는 팔 라듐 원소의 경우 LanL2DZ (Los Alamos National Laboratory double zeta)를, 나머지 원소에 대해서는 6-31 g(d)를 사용하였 다[8,9]. 계산은 Gaussian $09 \mathrm{~W}$ 계산화학 소프트웨어를 통해 이루어졌다[10].

\section{3. 결 과}

\section{1. 팔라듐 시드 제거를 위한 $\mathrm{KCN}$ 박리(KCN stripping) 공정의 도입 \\ ENEPIG의 도금 번짐이 팔라듐 활성화 공정에서 고분자 레}

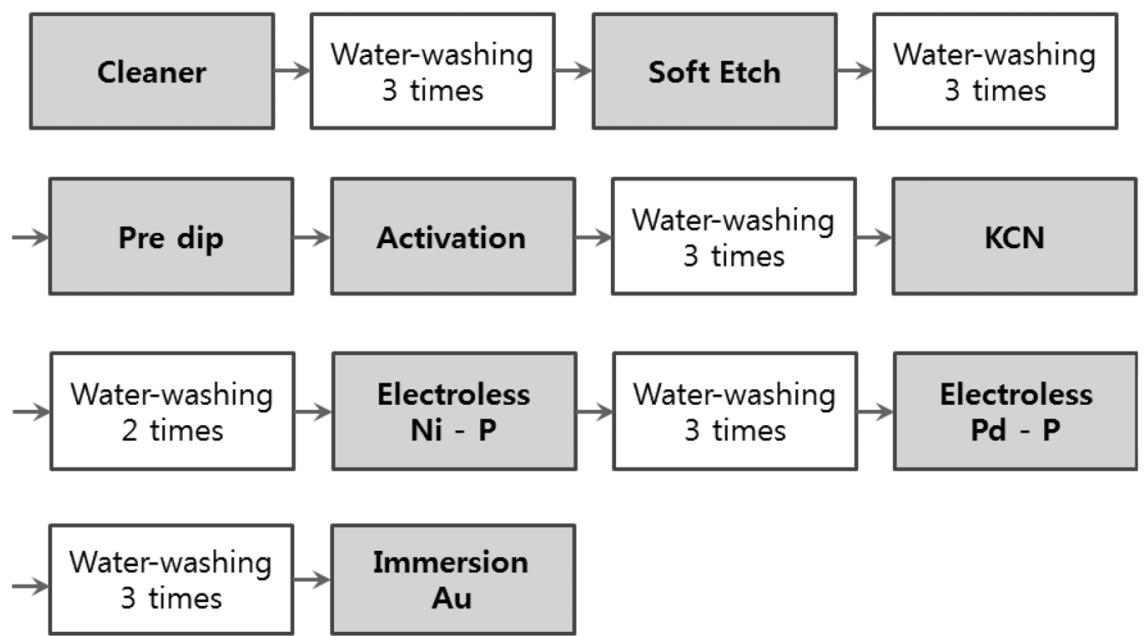

Figure 4. Flow of the ENEPIG process. 

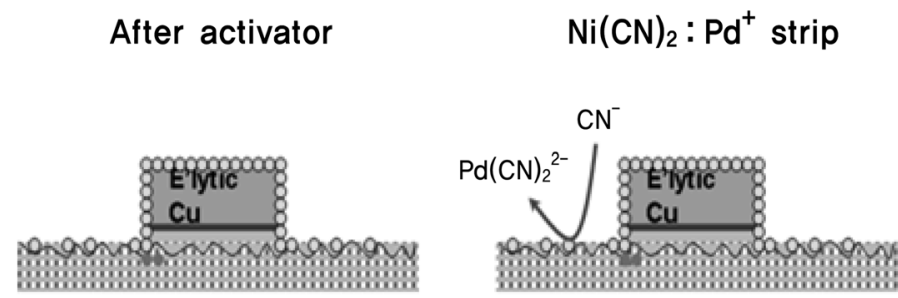

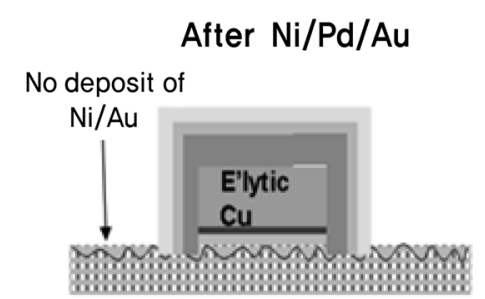

Figure 5. Concept of KCN stripping.

진 위에 형성되는 팔라듐 시드로부터 시작되는 것으로 판단되 어 Figure 5 와 같이 간단하게 $\mathrm{KCN}$ 박리를 함으로써 고분자 레진 위의 팔라듐 시드를 제거할 수 있었고 이에 Figure 4와 같이 정규 공정에 추가되었다. 원리는 간단하게 팔라듐 시드 를 $\mathrm{Pd}(\mathrm{CN})_{2}$ 의 형태로 녹여내는 것이다. 그러나 이 공정은 고 분자 레진뿐 아니라 패턴 위의 팔라듐도 녹여내어 공정 시간 조절에 실패할 경우 너무 박리되어 이후의 무전해 니켈 층이 올라가지 않거나 박리 시간이 짧은 경우 도금 번짐이 다시 발 생하였다. 특히 경박단소화로 인한 패턴의 피치가 줄어듦에 따라 $\mathrm{CN}^{-}$이온이 비아(via) 내로 확산(diffusion)되기 어려워 [6] 무전해 니켈 공정에 영향을 주지 않을 정도의 공정 시간 으로는 고분자 레진 위의 원하지 않는 팔라듐 시드를 효과적 으로 제거할 수 없어 도금 번짐이 지속적으로 발생하였다. 따 라서 근본적으로 팔라듐 시드가 생기지 않도록 하는 발상의 전환이 필요하다.

\section{2. 선택적 시드 형성(selective seeding)을 위한 팔라듐 활성화제 선정}

팔라듐 활성화 공정에서 패턴 위에 팔라듐 시드를 형성시키 기 위해 사용되는 팔라듐 촉매는 황산계인 $\mathrm{MNK}\left(\mathrm{PdSO}_{4}\right)$ 였다. 이에 염산계인 MSR-41 $\left(\mathrm{PdCl}_{2}\right)$ 을 사용하여 도금 번짐에 미치 는 팔라듐 촉매의 영향을 비교 실험하였다[11,12]. 실험에 앞 서 계산화학을 이용하여 두 가지 촉매 중에 어느 쪽이 고분자 레진 위에 팔라듐 핵 생성이 유리한지를 평가하였다. Figure 6과 같이 material studio visualizer (Accelrys사)를 이용하여 에 폭시(epoxy)를 적절한 길이로 구현하고 여기에 $\mathrm{PdCl}_{2}$ 와 $\mathrm{PdSO}_{4}$ 가 화학적으로 결합하는 에너지를 계산해 보았다. 계산 결과 $\mathrm{PdSO}_{4}$ 가 에폭시와 훨씬 화학적으로 세게 결합하여 에폭시 레 진 위에 팔라듐 시드로 발달하기 위한 핵 생성이 $\mathrm{PdCl}_{2}$ 에 비해 크게 유리한 것으로 판단되었다.

$$
\begin{aligned}
& \mathrm{PdCl}_{2}+\text { epoxy } \rightarrow \mathrm{PdCl}_{2} \text { epoxy } \quad-4.5 \mathrm{kcal} / \mathrm{mol} \\
& \mathrm{PdSO}_{4}+\text { epoxy } \rightarrow \mathrm{PdSO}_{4} \text { _epoxy }-14.6 \mathrm{kcal} / \mathrm{mol}
\end{aligned}
$$

Figure 7은 광학현미경으로 관찰된 패턴의 도금 번짐 정도 인데 염산계 팔라듐 촉매를 사용한 경우는 매우 선명한 패턴을 보여 주고 있으나 황산계 팔라듐 촉매의 경우는 패턴들 사이에 도금 번짐으로 인한 빛의 간섭(blurring) 관찰된다.
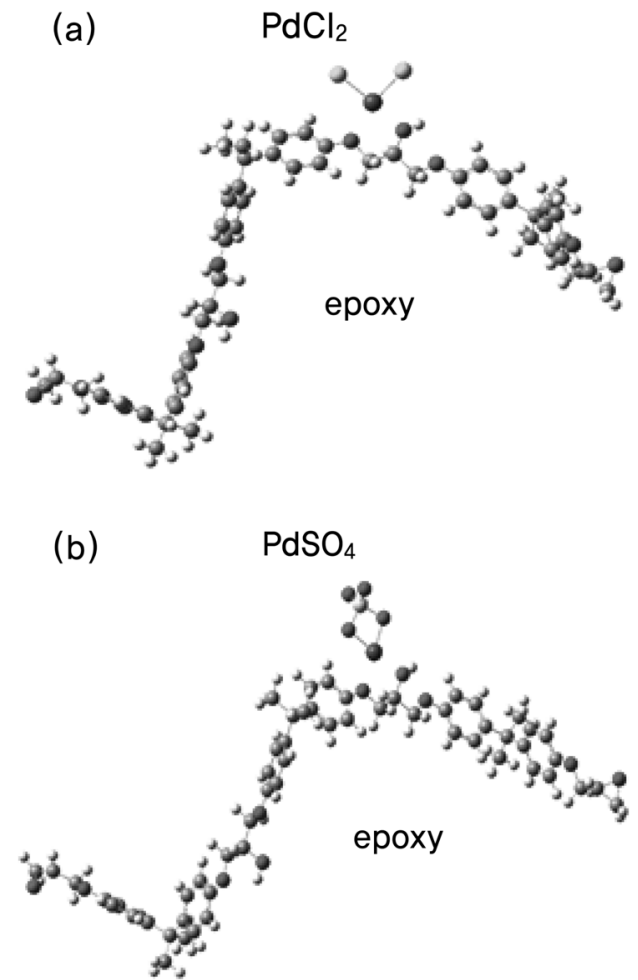

Figure 6. Computational formulation of $\left[\mathrm{PdCl}_{2}+\right.$ epoxy] (a) and $\left[\mathrm{PdSO}_{4}+\right.$ epoxy $]$ (b).
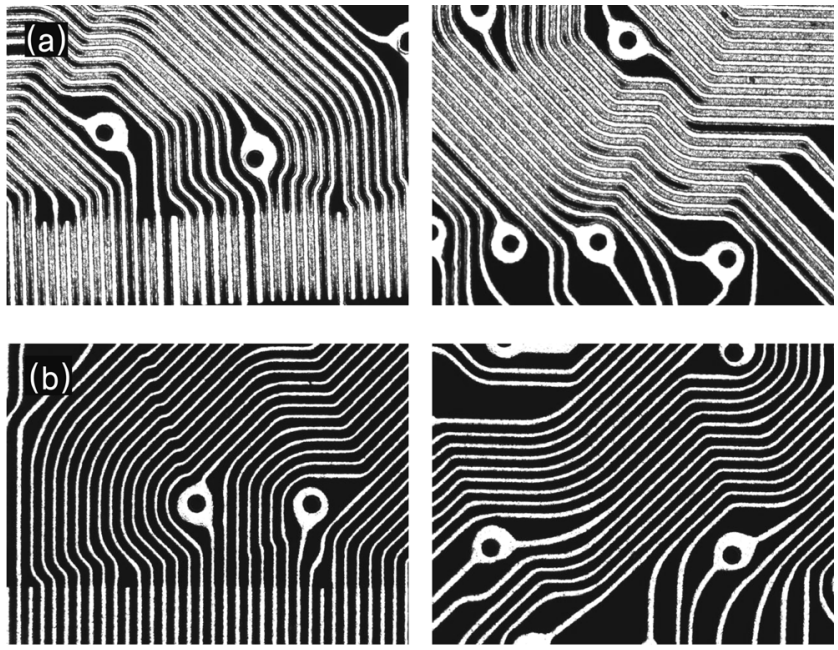

Figure 7. Optical micrographs $(\times 50)$ of the patterns using $\mathrm{H}_{2} \mathrm{SO}_{4}$ type $\mathrm{Pd}$ activator (a) and $\mathrm{HCl}$ type $\mathrm{Pd}$ activator (b) 


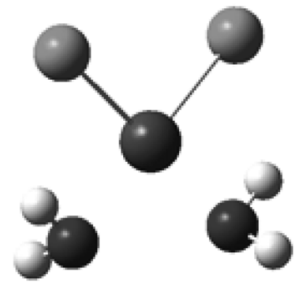

(a) $\mathrm{PdCl}_{2}\left(\mathrm{H}_{2} \mathrm{O}\right)_{2}$

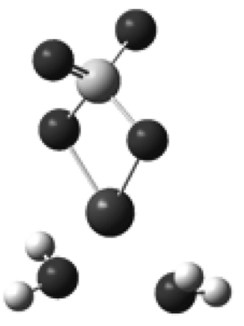

(b) $\mathrm{PdSO}_{4}\left(\mathrm{H}_{2} \mathrm{O}\right)_{2}$
Figure 8. Optimized geometries of the hydrate complexes of $\mathrm{PdCl}_{2}$ (a) and $\mathrm{PdSO}_{4}$ (b).

\section{3. 염산계 팔라듐 촉매를 사용한 팔라듐 활성화 공정의 최적화}

한편 $\mathrm{PdCl}_{2}$ 와 $\mathrm{PdSO}_{4}$ 는 수용액 중에서 각각 Figure 8의 수화 물로 존재한다.

$$
\begin{gathered}
\mathrm{PdCl}_{2}+2 \mathrm{H}_{2} \mathrm{O} \rightarrow \mathrm{PdCl}_{2}\left(\mathrm{H}_{2} \mathrm{O}\right)_{2} \quad-57.3 \mathrm{kcal} / \mathrm{mol} \\
\mathrm{PdSO}_{4}+2 \mathrm{H}_{2} \mathrm{O} \rightarrow \mathrm{PdSO}_{4}\left(\mathrm{H}_{2} \mathrm{O}\right)_{2}-60.1 \mathrm{kcal} / \mathrm{mol}
\end{gathered}
$$

$\mathrm{PdSO}_{4}\left(\mathrm{H}_{2} \mathrm{O}\right)_{2}$ 가 더 이상의 추가적인 반응이 없는 반면 $\mathrm{PdCl}_{2}$ $\left(\mathrm{H}_{2} \mathrm{O}\right)_{2}$ 는 반응 (5)와 (6)과 같은 추가적인 가수분해 반응에 의 해 $\mathrm{HCl}$ 을 생성하면서 안정한 $\mathrm{Pd}(\mathrm{OH})_{2}$ 를 형성한다. $\mathrm{Pd}(\mathrm{OH})_{2}$ 는 고분자 레진 위에서 팔라듐 시드로 성장하게 된다[13,14].

$$
\begin{aligned}
& \mathrm{PdCl}_{2}\left(\mathrm{H}_{2} \mathrm{O}\right)_{2} \rightarrow \operatorname{PdCl}(\mathrm{OH})\left(\mathrm{H}_{2} \mathrm{O}\right)+\mathrm{HCl} 50.1 \mathrm{kcal} / \mathrm{mol} \\
& \mathrm{PdCl}(\mathrm{OH})\left(\mathrm{H}_{2} \mathrm{O}\right) \rightarrow \mathrm{Pd}(\mathrm{OH})_{2}+\mathrm{HCl} \quad 38.5 \mathrm{kcal} / \mathrm{mol}
\end{aligned}
$$

비록 계산된 반응에너지 값이 매우 크지만 Figure 8의 수화물 형성 시 큰 발열반응을 고려하고 반응이 계산에서처럼 기상 에서 일어나는 것이 아니라 수용액 상에서 물 분자들의 용매화 (solvation) 효과를 수반하므로 $\mathrm{Pd}(\mathrm{OH})_{2}$ 의 형성은 가능하다. 더구나 두 개의 물 분자가 반응하여 두 개의 $\mathrm{HCl}$ 을 생성하므 로 엔트로피 측면에서도 불리한 점이 없다. 따라서 팔라듐 활 성화 공정의 온도는 낮을수록 $\mathrm{Pd}(\mathrm{OH})_{2}$ 의 생성이 적어지는 방 향이 될 수 있다. 또한 $\mathrm{HCl}$ 의 농도를 증가시켜주면 정반응이
감소하여 $\mathrm{Pd}(\mathrm{OH})_{2}$ 의 생성이 적어진다. 따라서 수용액 중에 $\mathrm{PdCl}\left(\mathrm{H}_{2} \mathrm{O}\right)^{3+}, \mathrm{PdCl}_{2}\left(\mathrm{H}_{2} \mathrm{O}\right)_{2}, \mathrm{PdCl}\left(\mathrm{H}_{2} \mathrm{O}\right)^{-}$등의 다양한 수화물 형태의 이온이나 화합물 대신에 후단의 수세공정을 통해 쉽게 제거될 수 있는 $\mathrm{PdCl}_{4}{ }^{2}$ 가 많이 생성된다[13,14]. Figure 9는 염 산계 MSR-41 팔라듐 촉매를 사용하고 염산의 농도를 증가시 키면서 도금 번짐의 정도를 관찰한 결과인데 염산의 농도가 증가할수록 도금 번짐이 줄어드는 것을 알 수 있다. Figure 7 과 같이 검은색으로 표시된 부분이 고분자 레진을 나타내며 이 부분의 길이 즉, 패턴 사이의 간격이 피치이다. 빛의 산란 이 없이 깨끗한 검은색으로 표시되는 것이 고분자 레진 위에 도금 번짐이 생기지 않았음을 의미한다.

이 밖에 도금 번짐의 유의 인자를 결정하기 위해 다양한 실 험을 한 결과를 간단하게 Table 2에 정리하였다. 연식각(soft etch)은 다양한 잔존 방청금속 성분을 제거하는 것이므로 공 정의 시간이 길어질수록 유리하였으며 팔라듐 활성화 공정의 온도는 앞선 언급했듯이 낮을수록 유리하였다. 팔라듐 활성 화 공정의 시간은 당연히 짧을수록 고분자 레진 위에 팔라듐 시드 생성이 감소하므로 도금 번짐 방지에 유리하며 팔라듐

\begin{tabular}{|c|c|c|c|c|}
\hline \multicolumn{2}{|c|}{ Parameter } & $\mathrm{S} / \mathrm{E}$ & Activator & Results \\
\hline \multirow{2}{*}{$\mathrm{S} / \mathrm{E}$ time } & $40 \mathrm{sec}$ & $40 \mathrm{sec}$ & \multirow{2}{*}{$\begin{array}{l}\mathrm{MNK}, 2 \mathrm{~min} \\
\mathrm{Pd} 45 \mathrm{mg}\end{array}$} & \multirow{2}{*}{$\begin{array}{l}\text { Improved with } \\
\mathrm{S} / \mathrm{E} \text { time } \uparrow\end{array}$} \\
\hline & $2 \mathrm{~min}$ & $2 \mathrm{~min}$ & & \\
\hline \multirow{2}{*}{$\begin{array}{l}\text { Pd activation } \\
\text { temperature }\end{array}$} & $20{ }^{\circ} \mathrm{C}$ & \multirow{2}{*}{$2 \mathrm{~min}$} & \multirow{2}{*}{$\begin{array}{l}\mathrm{MNK}, 2 \mathrm{~min} \\
\mathrm{Pd} 45 \mathrm{mg}\end{array}$} & \multirow{2}{*}{$\begin{array}{c}\text { Improved } \\
\text { with temp. } \downarrow\end{array}$} \\
\hline & $30{ }^{\circ} \mathrm{C}$ & & & \\
\hline \multirow{3}{*}{$\begin{array}{l}\text { Pd activation } \\
\text { time }\end{array}$} & $1 \mathrm{~min}$ & \multirow{3}{*}{$40 \mathrm{sec}$} & \multirow{3}{*}{$\begin{array}{l}\mathrm{MNK}, 2 \mathrm{~min} \\
\mathrm{Pd} 45 \mathrm{mg}\end{array}$} & \multirow{3}{*}{$\begin{array}{c}\text { Improved } \\
\text { with time } \downarrow\end{array}$} \\
\hline & $2 \min$ & & & \\
\hline & $3 \mathrm{~min}$ & & & \\
\hline \multirow{2}{*}{$\begin{array}{l}\text { Pd activation } \\
\text { concentration }\end{array}$} & $45 \mathrm{mg} / \mathrm{L}$ & \multirow[b]{2}{*}{$40 \mathrm{sec}$} & \multirow[b]{2}{*}{$\mathrm{MNK}, 1 \mathrm{~min}$} & \multirow{2}{*}{$\begin{array}{c}\text { Improved } \\
\text { with conc. } \downarrow\end{array}$} \\
\hline & $\begin{array}{r}12.5 \\
\mathrm{mg} / \mathrm{L} \\
\end{array}$ & & & \\
\hline \multirow{2}{*}{$\begin{array}{l}\text { Pd activator } \\
\text { type }\end{array}$} & MNK & \multirow[b]{2}{*}{$40 \mathrm{sec}$} & $\begin{array}{l}\mathrm{MNK}, 1 \mathrm{~min} \\
\mathrm{Pd} 12.5 \mathrm{mg}\end{array}$ & \multirow{2}{*}{$\begin{array}{c}\text { Improved } \\
\text { with MSR-41 } \\
\quad\left(\mathrm{PdCl}_{2}\right)\end{array}$} \\
\hline & MSR-41 & & $\begin{array}{c}\text { MSR-41, } \\
1 \mathrm{~min} \\
\mathrm{Pd} 12.5 \mathrm{mg}\end{array}$ & \\
\hline
\end{tabular}
촉매의 농도도 낮은 것이 유리하였다.

Table 2. Effect of the operational variables on the running blots between patterns

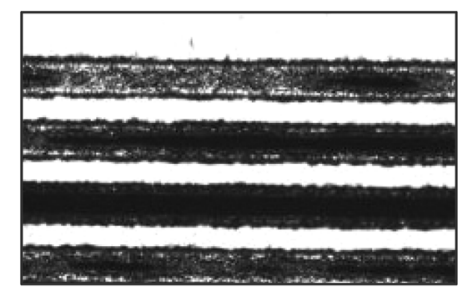

$\mathrm{HCl} 45 \mathrm{~mL} / \mathrm{L}$

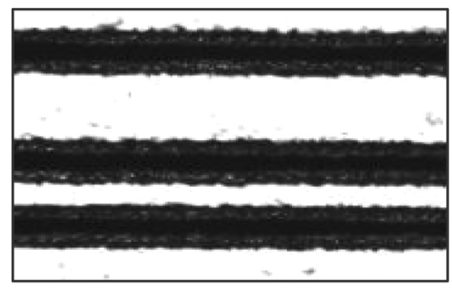

$\mathrm{HCl} 90 \mathrm{~mL} / \mathrm{L}$

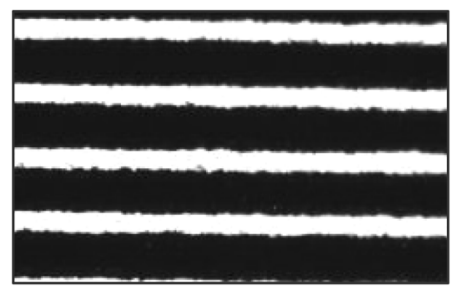

$\mathrm{HCl} 180 \mathrm{~mL} / \mathrm{L}$

Figure 9. Effect of the $\mathrm{HCl}$ concentration on the running blots between patterns observed by optical microscope $(\times 100)$. The pitch of the samples is $105 \mu \mathrm{m}$. 


\section{4. 결 론}

인쇄회로기판의 경박단소화로 인해 패턴 간의 피치가 감소 하면서 나타나는 무전해 니켈 - 팔라듐 · 금(ENEPIG) 표면처 리 공정의 도금 번짐 현상을 계산화학을 이용하여 물리화학적 으로 파악한 후 이를 바탕으로 개선 아이디어를 도출하였다. 도금 번짐이 팔라듐 활성화 공정에서 고분자 레진 위에 형성된 팔라듐 시드(seed)에 의해서 발생하는 것으로 가정하였으며 따 라서 팔라듐 시드가 생기지 않도록 하는 방향으로 접근하였다. 우선 $\mathrm{PdCl}_{2}$ 가 $\mathrm{PdSO}_{4}$ 보다 에폭시(epoxy)와 결합하는 정도가 약한 것을 계산화학으로 확인하였으며 이에 팔라듐 활성화 공 정의 팔라듐 촉매를 $\mathrm{HCl}$ 계 $\left(\mathrm{PdCl}_{2}\right)$ 로 교체하였다. $\mathrm{PdCl}_{2}$ 의 경 우 수용액 중에서 가수분해 반응에 의해 $\mathrm{HCl}$ 을 생성하면서 더 안정한 $\mathrm{Pd}(\mathrm{OH})_{2}$ 로 반응이 진행되므로 $\mathrm{HCl}$ 의 농도를 증가시 킴으로써 이를 막아 수세가 용이한 $\mathrm{PdCl}_{4}^{2-}$ 의 생성을 유도하였 다. 또한 팔라듐 활성화 공정의 온도를 낮게 유지함으로써 $\mathrm{PdCl}_{2}$ 수화물의 추가적인 반응을 방지하였다. 그 결과 ENEPIG 도금 번짐을 크게 개선할 수 있었으며 본 연구에서 사용한 계산화학 의 정성적인 분석은 해당 분야의 엔지니어들이 유익하게 활용 할 수 있는 접근법이라고 생각된다.

\section{감 사}

이 연구는 부경대학교 기성회계를 재원으로 한 신임교수 연 구력 강화지원사업의 지원을 받아 수행되어 감사드립니다.

\section{참고문헌}

1. http://www.pcb007.com/pages/zone.cgi?a=45348\&artpg=1\& topic $=0$

2. Yee, D. K. W., "Is Electroless Nickel/Electroless Palladium/ Imersion Gold (ENEPIG) the Solution of Lead Free Soldering on PCB and IC Packaging Applications?” Microsystems, Packaging, Assembly and Circuits Technology in IMPACT 2007, Taipei, 208-218 (2007).

3. Juanjuan, L., Zhenging, Z., and Lee, J., "Wire Bonding Performance and Solder Joint Reliability Investigation on ENEPIG Finish Substrate," 2010 11th International Conference on Electronic Packaging Technology \& High Density Packaging (ICEPT-HDP), Xi'an, 240-245 (2010).

4. Yoon, J.-W., Noh, B.-I., and Jung, S.-B., "Comparative Study of ENIG and ENEPIG as Surface Finishes for a Sn-Ag-Cu Solder Joint," J. Electron. Mater., 40, 1951-1955 (2011).

5. http://www.kitco.com/charts
6. Won, Y. S., Park, S. S., Lee, J., Kim, J.-Y., and Lee, S.-J., "The pH Effect on Black Spots in Surface Finish: Electroless Nickel Immersion Gold," Appl. Surf. Sci., 257, 56-61 (2010).

7. Hohenberg, P., and Kohn, W., "Inhomogeneous Electron Gas," Phys. Rev., 136, B864-B871 (1964).

8. Becke, A. D., "Density-functional Thermochemistry. III. The Role of Exact Exchange," J. Chem. Phys., 98, 5648-5653 (1993).

9. Ditchfield, R., Herhe, W. J., and Pople, J. A., "Self-Consistent Molecular-Orbital Methods. IX. An Extended Gaussian-Type Basis for Molecular-Orbital Studies of Organic Molecules," J. Chem. Phys., 54, 724-729 (1971).

10. Gaussian 09W, Revision C.01, Frisch, M. J., Trucks, G. W., Schlegel, H. B., Scuseria, G. E., Robb, M. A., Cheeseman, J. R., Scalmani, G., Barone, V., Mennucci, B., Petersson, G. A., Nakatsuji, H., Caricato, M., Li, X., Hratchian, H. P., Izmaylov, A. F., Bloino, J., Zheng, G., Sonnenberg, J. L., Hada, M., Ehara, M., Toyota, K., Fukuda, R., Hasegawa, J., Ishida, M., Nakajima, T., Honda, Y., Kitao, O., Nakai, H., Vreven, T., Montgomery, Jr., J. A., Peralta, J. E., Ogliaro, F., Bearpark, M., Heyd, J. J., Brothers, E., Kudin, K. N., Staroverov, V. N., Kobayashi, R., Normand, J., Raghavachari, K., Rendell, A., Burant, J. C., Iyengar, S. S., Tomasi, J., Cossi, M., Rega, N., Millam, J. M., Klene, M., Knox, J. E., Cross, J. B., Bakken, V., Adamo, C., Jaramillo, J., Gomperts, R., Stratmann, R. E., Yazyev, O., Austin, A. J., Cammi, R., Pomelli, C., Ochterski, J. W., Martin, R. L., Morokuma, K., Zakrzewski, V. G., Voth, G. A., Salvador, P., Dannenberg, J. J., Dapprich, S., Daniels, A. D., Farkas, Ö., Foresman, J. B., Ortiz, J. V., Cioslowski, J., and Fox, D. J., Gaussian, Inc., Wallingford CT, 2009.

11. Kaja, S., Mukherjee, S. P., O'Sullivan, E. J., and Paunovic, M., "Palladium Sulfate Solution for the Selective Seeding of the Metal Interconnections on Polyimide Dielectrics for Electroless Metal Deposition," U.S. Patent No. 5,380,560 (1995).

12. Watanabe, K., Nishiwaki, T., and Honma, H., "Evaluation of Activation Solution on Selective Electroless Nickel Deposition," 55th Annual Meeting of International Society of Electrochemistry, Thessaloniki, (2004).

13. Boily, J.-F., and Seward, T. M., "Palladium(II) Chloride Complexation: Spectrophotometric Investigation in Aqueous Solutions from 5 to $125{ }^{\circ} \mathrm{C}$ and Theoretical Insight into $\mathrm{Pd}-\mathrm{Cl}$ and Pd- $\mathrm{OH}_{2}$ Interactions," Geochimica et Cosmochimica Acta, 69, 3773-3789 (2005).

14. Simonov, P. A., Troitskii, S. Y., and Likholobov, V. A., "Preparation of the $\mathrm{Pd} / \mathrm{C}$ Catalysts: A Molecular-Level Study of Active Site Formation," Kinetics Catal., 41, 255-269 (2000). 